PACS 33.20.-t

Bakunina E. V., Dykyi O. V.

National University "Odesa Law Academy", 28, Rishel'evskaya str., Odesa, 65012

E-mail: bakuninaev09@gmail.com

\title{
SIGNAL PROCESSING AND CYBERSECURITY IN SOME CHAOTIC OPTICAL COMMUNICTAION SYSTEMS
}

\begin{abstract}
A chaos -geometric approach to investigation of complex chaotic dynamical systems is applied to an analysis, modeling and processing the time series of emission intensities of chaotic transmitter/receiver systems (two unidirectionally coupled semiconductor laser systems in the all-optical scheme) suited for encoding at rates of GBit/s. the problem of a signal processing is directly connected with the corresponding cybersecurity in some optical chaos communictaion systems. The estimated values for the dynamic and topologic invariants such as the correlation and Kaplan-York dimensions, Lyapunov indicators, Kolmogorov entropy etc for investigated chaotic signal time series of two unidirectionally coupled semiconductor laser systems in the all-optical scheme.
\end{abstract}

1. At present time there are carried out the intensive investigations in the field of signal processing and cybersecurity in different optical chaos communictaion systems that is provided by a great importance and interst due to its technical applicatioons [1-6].

The use of methods of a chaos theory has been considered as an effective alternative technique to encrypt information that provides a high level of cyber security for complex information. There have been published sufficiently large number of papers, but, hitherto it is absent an full understanding all mathematical computational, informational and technological aspects of this problem (c.g., $[1,2]$ and Refs therein).

According to ref. [1,2], there are papers, where it has been shown that a message could be encoded and decoded within a high dimensional chaotic carrier in devices with using coupled single-mode semiconductor lasers subjected to coherent optical feedback or injection, or erbium doped fiber ring lasers.

The important feature of such schemes is connected with successful possibilities to synchronize two spatially separated chaotic semiconductor lasers to each other. The authors [2] have reviewed review the main characteristics of the emitter/receiver devices concentrating on two kind of chaotic systems: a semiconductor laser subject to a delayed all-optical feedback and a semiconductor lasers subject to a delayed non-linear electro-optical feedback. The important result of Ref. [2] are as follows: firstly, there is generated a direct-chaotic carrier in dynamics of both systems; secondly, availability of chaotic regime in systems sufficient to provides a privacy in the communication as the higher the complexity of the chaotic carrier the more difficult is to decode the message without the appropriate receiver [2].

From the technical viewpoint, message can be hidden in the broad spectrum in the $10-100 \mathrm{GHz}$ range due to the use of semiconductor diode lasers. In Refs. [10-10] the authors presented a general, uniform chaosgeometric formalism to analysis, modelling and prediction of the non-linear dynamics of quantum and laser systems and devices ( such as atomic and diatomic systems in an electromagnetic infrared field, laser and quantum generators systems etc) with elements of the deterministic chaos. In particular, the detailed analysis and modelling has been realized and the results of studying the low- and high dimensional dynamics of a chaos generation in the semiconductor GaAs/GaAlAs laser with the retarded feedback as well as the results of non-linear analysis of the chaotic oscillations in a grid o two autogenerators have been listed. It should be noted that the dynamics of this systems has been also studied from the viewpoint of the corresponding differential equations solutions (e.g. $[12,24,44])$. At the same time, in a case of different quite complex systems a 
similar analysis and differential equations solving is not possible at least in the simplified form, so here one may make processing the experimental time series of the fundamental dynamical variables.

Through there are many papers, where the different methods and algorithms of processing temporal and spatial dynamics of the complex systems are developed and intensively used (see references [1-24].

However, below we will follow a chaos geometric approach, developed in refs. [2020]. It includes the advanced generalized techniques such as the wavelet analysis, multi-fractal formalism, mutual information approach, correlation integral analysis, false nearest neighbour algorithm, the Lyapunov exponent's analysis, and surrogate data method, and principally new methods and algorithms of prediction etc.

In this paper we apply a chaos -geometric approach to analysis, modeling and processing the time series of emission intensities of chaotic transmitter/receiver systems (two unidirectionally coupled semiconductor laser systems in the all-optical scheme) suited for encoding at rates of GBit/s [2].

We will list the estimated values for the dynamic and topologic invariants such as the correlation and Kaplan-York dimensions, Lyapunov indicators, Kolmogorov entropy etc for investigated chaotic signal time series.

According to Refs. [20-20], the general chaos-geometric scheme of analysis, modeling and processing the time series of the cited intensities time series includes the following points. The first point is processing the input data, which contain a time series with $\mathrm{N}$ discrete values of the scalar variable, namely, intensity measurements:

$$
I(t)=I\left(t_{0}+j \Delta t\right)=I(j)
$$

So the first step is connected with preparing the corresponding numerical data about the intensity measurements. In the general case, $s$ (n) can be any time series (populations or polarization of atoms or molecules, radiation intensities of systems, etc.).
In our case below speech is about the time series of emission intensities of chaotic transmitter/receiver systems (two unidirectionally coupled semiconductor laser systems in the all-optical scheme). This scheme is in details described in Ref. [2]. It is a characteristic feature of this system is availability of a hyper-chaotic carrier, i.e. a high dimensional chaotic attractor. This circumstance has a direct relation to ensuring privacy in the communication as the higher complexity of a chaotic carrier the more difficult is to decode the message without the appropriate receiver (see details in Ref. [2]). Usually these characteristic can be provided by using the semiconductor diode lasers, which, according to different estimates, are able to exhibit a broad spectrum in the range about 10$100 \mathrm{GHz}$.

The characteristics of chaotic systems signals (time series) and respectively a mechanism of encoding the messages are realized by such a way with a guarantee of impossibility to extract the message by means of any linear filtering process etc. The technical parameters of the chaotic optical communication system are described in ref. [2].

Here we only note that the setup is used to study experimentally all-optical chaos phenomenon. It consists of an external cavity semiconductor laser and several detection devices, namely, a cavity semiconductor laser consists of an edge emitting laser which is driven by a low noise direct current source, a collimation lens, a variable neutral density filter and a high reflecting mirror with a reflectivity of approximately $99 \%$ terminating the external cavity [2]. The semiconductor laser with the facet reflectivities is electronically pumped by a low noise current source with the injection current $\mathrm{I}_{\mathrm{DC}}$. The internal round trip time of the light is $\tau$. The emitted light is reflected from a distant mirror with the reflectivity and reinjected into the laser system with some time delay.

A system is constructed so in order to use chaotic fluctuations of intensity (-or amplitude) of a semiconductor laser. As a rule, one keep in mind that some message is masked as a small amplitude modulation with a masking 
efficiency (order about -15 dB). In Ref. [2] there are presented the data on the temporal intensity dynamics obtained for an injection current of $\mathrm{I}_{\mathrm{DC}}=1.2 \mathrm{I}_{\text {th }}$ and a length of the external cavity $3.9 \mathrm{~cm}$. The temporal dynamics comprises fast chaotic pulsations in the $\mathrm{GHz}$ range representing as chaotic carrier signal for communication experiments.

From the theoretical viewpoint, analysis of the corresponding time series in further includes reconstruction of the phase space of a system.

More exactly, according to Refs. [20-20], speech is about calculation the respective embedding dimension and reconstruction of an Euclidean space large enough so that the set of points $d_{A}$ can be unfolded without ambiguity. The well-known approach to perform this reconstruction is in utilizing the correlation dimension method, which allows to calculate so called correlation integral and its dependence upon a radius of the correlation sphere. There are a few versions of numerical realization of the correlation dimension algorithm.

Usually, simultaneously one should check the correctness of the processed data by means of utilizing a surrogate data algorithm (see al details in Refs. [20-20]), which allows to create the substitute data sequences generated in accordance to the probabilistic structure underlying the original data.

It is important to underline that simulteniously an autociolrelation function alsofythm as well as method of average mutual information are utilized to calculate very important numerical parameter of the all algorithm such as a delay time $v$ (or lag). The matter is in the fact that the series (1) is exchanged by the series with delayed variables I $(j+v)$ and further one should construct the corresponding vector in the D-dimensional space:

$$
[I(j), I(j+v), I(j+2 v), \ldots, I(j+(D-1) v)] .
$$

It should be noted As it has been noted in [20], if a number $v$ is too big, then $I(j+n v)$ and $I(J+(n+1) v)$ will be completely independent of each other in the statistical sense and the projections of the orbits on the attractor will be directed at two completely unrelated directions.

In order to check any complex system on an availability of the elements of a chaos any researcher usually utilizes a procedure of calculation of the such important dynamical invariants as the Lyapunov indicators $\delta_{\mathrm{i}}$ (look details in Refs. [17-20]). These indicators determine an invariant measure of chaotic attractor. The latter are very useful when considering the physics of the process and, moreover, determine the limited predictability of the chaotic motion of the physical system. Using only topological or only dynamic invariants to characterize the attractor is unlikely to give a "complete" set of invariants, so it is necessary to use them together. It is worth to remind that there is another very important characteristics such as Kolmogorov entropy $E_{K}$ which is defined as a sum of the positive Lyapunov indicators.

In order to calculate a dimension of the chaotic attractor one could use the KaplanYork formula :

$$
\mathrm{D}_{\mathrm{L}}=\mathrm{i}+\sum_{\mathrm{m}=1}^{\mathrm{i}} \delta_{\mathrm{m}} /\left|\delta_{\mathrm{i}+1}\right|,
$$

where the Lyapunov's exponents $\delta$ are taken in descending order, and the number is such that the quantities $\sum_{m=1}^{i} \delta_{m}>0$ and $\sum_{m=1}^{i+1} \delta_{m}<0$. To calculate the Lyapunov indicators $\delta_{\mathrm{i}}$, one could use one of the existing numerical algorithms and the corresponding PC codes. In this paper we have used the algorithm, which is based on the Jacobi matrix of system and the numerical codes Tisean, Quantum Chaos and Geomath [20]). The details of the utilized methods and algorithms can be found in Refs. [20-20].

3. Below we present the concrete data of analysis and modeling time series of emission intensities of chaotic transmitter/receiver systems (two coupled semiconductor laser systems in the all-optical scheme) suited presented in Ref. [2] for encoding at rates of GBit/s; the typical time series of emission 
intensities of chaotic transmitter/receiver systems with two coupled semiconductor laser systems is presented in figure 1 .

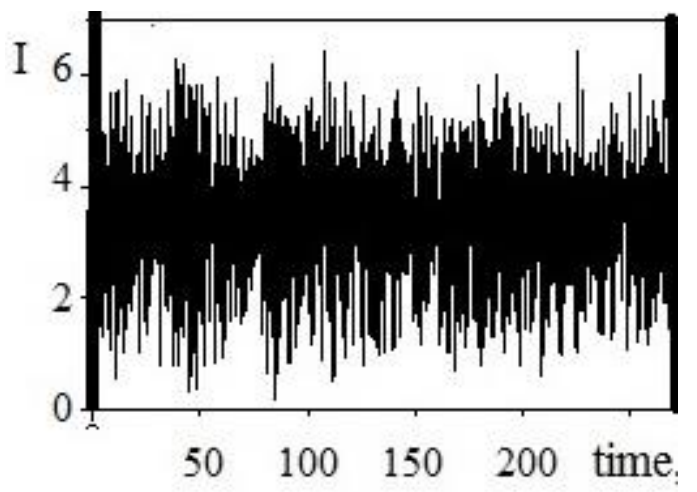

Figure 1. A typical time (ns) series of emission intensity I of the chaotic transmitter/receiver system with two coupled semiconductor laser systems $\left(8 \times 10^{3}\right.$ points and $\left.\Delta t=0.0125 \mathrm{~ns}\right)$.

The concrete step is an analysis of the corresponding time series with $8 \times 10^{3}$ points and $\Delta t=0.0125 \mathrm{~ns}$. The corrective algorithms have been used in order to reconstruct the missing time series terms. The calculation allows to get the following values of the main topologic and dynamic invariants, namely, the time lag $v=8$, the embedding dimension $\mathrm{D}_{\mathrm{E}}=5$, the correlation dimension $\mathrm{D}_{\mathrm{C}}=3.2$, the Kaplan-York dimension: $\mathrm{D}_{\mathrm{L}}=2.3$, the positive and negative Lyapunov indicators $\delta_{1}=0.233, \delta_{2}=0.003, \delta_{3}=-0.004, \ldots$, the Kolmogorov entropy: $E_{K}=0.236$. Surely, there is an important chaos availability parameter such as the Gottwald-Melbourne $\mathrm{E}_{\mathrm{gm}}$, however here we did not calculate $\mathrm{E}_{\mathrm{gm}}$. The performed calculation allows to pay attention at a few important dynamic features in the system. Firstly, availability of two positive Lyapunov indicators is an evidence of a chaos availability in the temporal dynamics and existence of the respective strange attractor in a phase space.

It is important to underline that the Kaplan-York dimension is very close to the correlation dimension, but indeed is smaller than the embedding dimension. The latter confirms the correctness of the choice of the latter. In order to conclude, let us underline that in this work a chaos -geometric ap- proach (in versions [20-20]) has been applied to investigation of complex chaotic optical communication dynamical systems with the aim of modeling and processing data of the time series for emission intensities of chaotic transmitter/receiver systems.

The latter is provided by using two unidirectionally coupled semiconductor laser systems of Ref. [2]. The numerical data on the some dynamic and topologic invariants (the correlation and embedding dimensions, the Kaplan-York parameter, the Lyapunov indicators, Kolmogorov entropy) for investigated chaotic signal time series are obtained and analyzed in order to estimate quantitatively the chaos phenomenon in characteristic chaotic optical communication system. It is important to underline that a changing the governed parameters in a system will result in changing the main dynamic and topologic parameters and can be performed in regime of the numerical experiment.

As the problem of a signal processing in investigated chaotic optical communictaion system is directly connected with the corresponding cybernetic security, it is obvious that the obteined data on the chaotic dynamic parameters and carrier can be utilized for indirect estimate of a privacy in the communication as the higher the complexity of the carrier the more difficult is to decode a e message without the appropriate receiver [2].

\section{References}

1. Feature Section on Optical Chaos and Applications to Cryptography, IEEE vol. 38, Ed. by S. Donati and C. R.Mirasso, IEEE J. Quantum Electron., 2002.

2. Mirasso, C.R., Fischer I., Peil M., Larger L. Optoelectronic Devices For Optical Chaos Communications. Proc. Spie 5248, Semiconductor Optoelectronic Devices For Lightwave Communication (8 Dec. 2003).

3. Bakunina E.V., Dikyi O.V., Signal processing and cybersecurity in some information technology systems: Chaosgeometric approach. These add. AllUkrainian scientific-practical. Conf. 
"Cybersecurity in the modern world: current challenges" ("Odessa Law Academy"). 2020.

4. Schreiber, T. Interdisciplinary application of nonlinear time series methods. Phys.Rep. 1999, 308, 1-64.

5. Glushkov, A.V. Methods of a Chaos Theory. Astroprint: Odessa, 2012

6. Abarbanel, H.; Brown, R.; Sidorowich, $\mathrm{J}$; Tsimring, L. The analysis of observed chaotic data in physical systems. Rev. Mod. Phys. 1993, 65, 1331- 1392.

7. Kennel, M.; Brown, R.; Abarbanel, H. Determining embedding dimension for phase-space reconstruction using geometrical construction. Phys. Rev. A. 1992, 45, 3403-3412.

8. Glushkov A.V., Khetselius O.Y., Brusentseva S.V., Zaichko P.A., Ternovsky V.B., Studying interaction dynamics of chaotic systems within a nonlinear prediction method: application to neurophysiology. In Advances in Neural Networks, Fuzzy Systems and Artificial Intelligence, Series: Recent Advances in Computer Engineering, Ed. J.Balicki.(Gdansk, WSEAS Pub.) 2014, 21, 69-75.

9. Glushkov, A.V. Atom in an electromagnetic field. KNT: Kiev, 2005.

10. Khetselius, O. Forecasting evolutionary dynamics of chaotic systems using advanced non-linear prediction method In Dynamical Systems Applications; Lódz, 2013; Vol T2, pp 145-152.

11. Glushkov, A.V.; Khetselius, O.Yu.; Brusentseva, S.; Duborez, A. Modeling chaotic dynamics of complex systems with using chaos theory, geometric attractors, and quantum neural networks. Proc. Intern. Geometry Center. 2014, 7(3), 87-94.

12. Glushkov, A.V.; Malinovskaya, S.V.; Shpinareva, I.M.; Kozlovskaya, V.P.; Gura, V.I. Quantum stochastic modelling energy transfer and effect of rotational and v-t relaxation on multi-photon excitation and dissociation for $\mathrm{CF}_{3} \mathrm{Br}$ molecules. Int. Journ. Quant. Chem. 2005, 104(4), 512-516.
13. Glushkov, A.V.; Buyadzhi, V.V.; Ponomarenko, E.L. Geometry of Chaos: Advanced approach to treating chaotic dynamics in some nature systems. Proc. Int. Geom. Center. 2014 7(1),24-30.

14. Glushkov A., Ternovsky V., Buyadzhi V, Prepelitsa G. Geometry of a relativistic quantum chaos: New approach to dynamics of quantum systems in electromagnetic field and uniformity and charm of a chaos. Proc. Int. Geom. Center. 2014, 7(4), 60-71.

15. Glushkov A.V.; Ivanov, L.N. DC strongfield Stark effect: consistent quantummechanical approach. J. Phys. B: At. Mol. Opt. Phys. 1993, 26, L379-386

16. Glushkov, A.V. Relativistic Quantum theory. Quantum mechanics of atomic systems. Astroprint: Odessa, 2008.

17. Khetselius, O.Yu. Quantum structure of electroweak interaction in heavy finite Fermi-systems. Astroprint: Odessa, 2011.

18. Glushkov, A.; Ambrosov, S.; Ignatenko, A. Non-hydrogenic atoms and WannierMott excitons in a DC electric field: Photoionization, Stark effect, Resonances in ionization continuum and stochasticity. Photoelectronics, 2001, 10, 103-106.

19. Khetselius, O.. Relativistic perturbation theory calculation of the hyperfine structure parameters for some heavy-element isotopes. Int. Journ.Quant.Chem. 2009, 109, 3330-3335.

20. Glushkov, A.V.; Ternovsky, V.B.; Buyadzhi, V.; Prepelitsa, G.P. Geometry of a Relativistic Quantum Chaos: New approach to dynamics of quantum systems in electromagnetic field and uniformity and charm of a chaos. Proc. Intern. Geom. Center. 2014, 7(4), 60-71.

21. Kuznetsova, A.A.; Glushkov, A.V.; Ignatenko, A.V.; Svinarenko, A.A.; Ternovsky V.B. Spectroscopy of multielectron atomic systems in a DC electric field. Adv. Quant. Chem. (Elsevier) 2018, 78, 287-306.

22. Glushkov, A., Buyadzhi, V., Kvasikova, A., Ignatenko, A., Kuznetsova, A., Pre- 
pelitsa, G., Ternovsky, V. Non-Linear chaotic dynamics of quantum systems: Molecules in an electromagnetic field and laser systems. In: Quantum Systems in

Physics, Chemistry, and Biology. Springer, Cham. 2017, 30, 169-180

23. Glushkov A., Khetselius O., Bunyakova Yu., Prepelitsa G., Solyanikova E., Serga E. Non-linear prediction method in short-range forecast of atmospheric pollutants: low-dimensional chaos. In: $D y$ namical Systems - Theory and Applications. Lodz Univ. 2011, LIF111

24. Glushkov A., Khetselius O., Kuzakon V., Prepelitsa G., Solyanikova E., Svinarenko A. Modeling of interaction of the non-linear vibrational systems on the basis of temporal series analyses (application to semiconductor quantum generators). Dynamical Systems - Theory and Applications. Lodz. 2011, BIF110.

25. Glushkov, A.V., Khetselius, O.Yu., Svinarenko, A., Buyadzhi, V. Methods of computational mathematics and mathematical physics. P.1. Odessa: 2015.

26. Ignatenko A., Buyadzhi A., Buyadzhi V., Kuznetsova, A.A., Mashkantsev, A.A., Ternovsky E. Nonlinear chaotic dynamics of quantum systems: molecules in an electromagnetic field. $A d v$. Quant Chem. 2019, 78, 149-170.

27. Mashkantsev, A. A. ; Ignatenko, A.V. ; Kirianov, S.V. ; Pavlov, E.V. Chaotic dynamics of diatomic molecules in an electromagneic field. Photoelectronics. 2018, 27, 103-112.

PACS 33.20.-t

Bakunina E.V., Dykyi O.V.

\section{SIGNAL PROCESSING AND CYBERSECURITY IN SOME CHAOTIC OPTICAL COMMUNICTAION SYSTEMS}

Summary. A chaos - geometric approach to investigation of complex chaotic dynamical systems is applied to an analysis, modeling and processing the time series of emission intensities of chaotic transmitter/receiver systems (two unidirectionally coupled semiconductor laser systems in the all-optical scheme) suited for encoding at rates of GBit/s. The problem of a signal processing is directly connected with the corresponding cybersecurity in some optical chaos communictaion systems. The estimated values for the dynamic and topologic invariants such as the correlation and Kaplan-York dimensions, Lyapunov indicators, Kolmogorov entropy etc for investigated chaotic signal time series of two unidirectionally coupled semiconductor laser systems in the all-optical scheme.

Key words: complex chaotic dynamical systems, signal processing and cybersecurity 
Бакунина Е.В., О.В. Дикий

\section{ОБРАБОТКА СИГНАЛОВ И КИБЕРБЕЗОПАСНОСТЬ В НЕКОТОРЫХ ХАОТИЧЕСКИХ ОПТИЧЕСКИХ СИСТЕМАХ КОММУНИКАЦИИ}

Резюме. Хаос-геометрический подход к исследованию сложных хаотических динамических систем применяется для анализа, моделирования и обработки временных рядов интенсивности излучения хаотических систем передатчика/приемника (две связанные полупроводниковые лазерные системы в полностью оптической схеме), пригодные для кодирования со скоростью порядка Гбит /с. Вопрос обработки и кодирования сигналов непосредственно связано с соответствующим вопросом кибербезопасности в соответствующих хаотических оптических системах связи. Выполнен расчет значений динамических и топологических инвариантов, таких как корреляционная размерность, размерность Каплана-Йорка, показатели Ляпунова, энтропия Колмогорова и др., для изучаемых временных рядов хаотического сигнала двух связанных полупроводниковых лазерных систем в общей оптической схеме.

Ключевые слова: сложные хаотические динамические системы, связанные полупроводниковые лазерные системы, обработка сигналов и кибербезопасность

PACS 33.20.-t

Бакуніна Є.В., О.В. Дікий

\section{ОБРОБКА СИГНАЛІВ І КІБЕРБЕЗПЕКИ В ДЕЯКИХ ХАОТИЧНИХ ОПТИЧНИХ СИСТЕМАХ КОМУНІКАЦЇ̈}

Резюме. Хаос-геометричний підхід до дослідження складних хаотичних динамічних систем застосовується для аналізу, моделювання та обробки часових рядів інтенсивності випромінювання хаотичних систем передавача / приймача (дві пов'язані напівпровідникові лазерні системи в повністю оптичній схемі), придатні для кодування зі швидкістю Гбіт / с. Питання обробки та кодування сигналів безпосередньо пов'язане із відповідним питанням кібербезпеки у відповідних хаотичних оптичних системах зв'язку. Виконаний розрахунок значень динамічних та топологічних інваріантів, таких як кореляційна розмірність, розмірність Каплана-Йорка, показники Ляпунова, ентропія Колмогорова та ін., для вивчаємих часових рядів хаотичного сигналу двох пов'язаних напівпровідникових лазерних систем у загальнооптичній схемі.

Ключові слова: складні хаотичні динамічні системи, пов'язані напівпровідникові лазерні системи, обробка сигналів та кібербезпека. 